Cost-effectiveness of seasonal influenza vaccination in pregnant women, health care workers and persons with underlying illnesses in Belgium Peer-reviewed author version

Blommaert, Adriaan; Bilcke, Joke; VANDENDIJCK, Yannick; Hanquet, Germaine; HENS, Niel \& Beutels, Philippe (2014) Cost-effectiveness of seasonal influenza vaccination in pregnant women, health care workers and persons with underlying illnesses in Belgium. In: VACCINE, 32 (46), p. 6075-6083.

DOI: $10.1016 / j$. vaccine.2014.08.085

Handle: http://hdl.handle.net/1942/17969 


\section{Cost-effectiveness of seasonal influenza vaccination in pregnant women, health 2 care workers and persons with underlying illnesses in Belgium}

3 Adriaan Blommaert ${ }^{1,2^{*}}$, Joke Bilcke ${ }^{1}$, Yannick Vandendijck ${ }^{2}$, Germaine Hanquet ${ }^{3}$,Niel Hens ${ }^{1,2}$ and Philippe

4 Beutels ${ }^{1,4}$

$5 \quad{ }^{1}$ Centre for Health Economics Research and Modelling Infectious Diseases (CHERMID), Vaccine \&

6 Infectious Disease Institute (VAXINFECTIO), University of Antwerp, Antwerp, Belgium

$7 \quad{ }^{2}$ Interuniversity Institute for Biostatistics and statistical Bioinformatics (I-BIOSTAT), Hasselt University,

8 Hasselt, Belgium

$9{ }^{3}$ Belgian Health Care Knowledge Centre (KCE), Brussels, Belgium

$10{ }^{4}$ School of Public Health and Community Medicine, The University of New South Wales, Sydney, Australia

$11{ }^{*}$ Corresponding author. Tel.: +32 32652937 ; E-mail address: adriaan.blommaert@uantwerp.be;

12 Address: Universiteitsplein 1 R2.12, BE2610 Wilrijk (Antwerpen); Belgium

\section{Abstract}

Risk groups with increased vulnerability for influenza complications such as pregnant women, persons with underlying illnesses as well as persons who contact them, such as health care workers, are currently given priority (along with other classic target groups) to receive seasonal influenza vaccination in Belgium. We aimed to evaluate the efficiency of this policy by performing cost-effectiveness analysis of increased vaccine uptake in the three specific target groups above, while accounting for effects beyond the target group. Increased influenza vaccine coverage is likely to be cost-effective for pregnant women (median €6,589 per Quality-Adjusted Life-Year (QALY) gained [€4,073-€ 10,249]) and health care workers (median €24,096/QALY gained [16,442-€36,342]), if this can be achieved without incurring additional administration costs. Assuming an additional physician's consult is charged to administer each additional vaccination, the cost-effectiveness of vaccinating pregnant women depends strongly on the extent of its impact on the neonate's health. For health care workers, the assumed number of preventable secondary infections has a strong influence on the cost-effectiveness. Vaccinating people with underlying illnesses is likely highly cost-effective above 50 years of age and borderline cost-effective for younger persons, depending on how this risk group's life expectancy compares to that of the general population. The casefatality ratios of the target group, of the secondary affected groups and vaccine efficacy are key sources of uncertainty. 
Seasonal influenza causes a substantial number of symptomatic infections, hospitalisations and fatalities, especially in young children, the elderly and people with underlying illnesses [1]. The Superior Health Council of Belgium recommends giving priority to immunizing people at increased risk of influenza complications, namely people living in institutions, people with underlying illnesses and the elderly (>65 years). Furthermore, health care workers ( $\mathrm{HCWs}$ ), pregnant women in the $2^{\text {nd }}$ and $3^{\text {rd }}$ trimester of pregnancy, the general population between 50 and 64, and poultry and pig farmers and their household members, have priority over the general population [2]. Prioritization is important, because the demand for influenza vaccines has surpassed supply in recent years [3]. Although these recommendations were based on the medical literature, their potential cost-effectiveness was largely unknown. Also, doubts have been expressed about the usefulness of influenza vaccination in view of uncertainties related to season-specific effectiveness in at-risk groups [4]. Therefore, up to date information on the costeffectiveness of vaccinating these risk groups, may improve the prioritisation and acceptability of seasonal influenza vaccines. In this paper, we evaluate the cost-effectiveness of increasing seasonal influenza vaccine uptake in (1) pregnant women in their $2^{\text {nd }}$ and $3^{\text {rd }}$ trimester, (2) HCWs and (3) people with underlying illnesses. Currently these groups have relatively low vaccine uptake [3], despite the above recommendations. Cost-effectiveness analyses of influenza vaccination of the elderly are presented elsewhere in combination with childhood vaccination options using a dynamic transmission model [3]. We did not consider here the specific risk group of poultry and pig farmers, because the rationale for their vaccination (recombination of viruses in their work environment with potential risk to the general population) requires a different modelling approach.

The cost-effectiveness of vaccinating pregnant women [5-7], HCWs [8-11] and people with underlying illnesses [12-16] has been evaluated before in other countries, but the results depended strongly on assumed vaccine efficacy. In this study, we use the most up to date estimates [17], and consider the potential impact of influenza vaccination beyond the target group. Vaccination during pregnancy has the potential to reduce foetal death through avoided maternal mortality, and confers vaccine-induced immunity to the neonate [18]. In previous cost-effectiveness analyses, these potential effects were not $[5,7]$ or only partially [6] accounted for. Vaccinating HCWs was also shown to have an effect on the patients and the elderly in general, and is therefore also considered in our analyses. 


\section{Material and methods}

Since the groups of pregnant women, HCWs and people with underlying illness are relatively small in Belgium and are not core transmitter groups for the influenza virus, the cost-effectiveness of their vaccination can be analysed using a static model [21]. For each risk group, a decision tree model was developed in the R software. (R development Core Team, 2012, http://www.R-project.org). The general structure is displayed in Figure 1 and model parameters are listed in Table 1 . The model assumes that susceptible individuals (unvaccinated or vaccinated without being protected) experience an age dependent rate of acquiring a symptomatic influenza infection for which they seek medical care. This rate is based on estimates from a dynamic model for influenza like illness (ILI) fitted to ILI surveillance data [3], combined with laboratory confirmed influenza proportions on these ILI data. We obtained the total number of symptomatic cases and thence the age-specific number of cases who do and do not seek medical care (i.e. do not consult a physician). Thus we obtained the number of cases not receiving medical care, ambulatory cases, hospitalisations and fatalities.

Direct medical costs and QALY losses associated with these outcome categories were included in order to compare the costs and QALYs of current with increased vaccine uptake scenarios (up to 50\% (40\% for persons with underlying illnesses)) [1]. A health care payer perspective was used. Costs and non-fatal health outcomes were not discounted because of the short analytical time horizon (one year). Future life-years lost due to influenza-attributable mortality were discounted at an annual rate of $1.5 \%$, in accordance with Belgian guidelines [22].

We assumed the vaccine is offered to pregnant women, on average in calendar week 47 (i.e. midNovember). We assumed also a 4-week delay before vaccinees benefit from vaccine protection. Hence, costs and QALY losses were included for infections occurring between calendar week 51 and 25 (assumed end of the influenza season), by using a partial attack rate in the model ( $84 \%$ of the yearly ILI cases occurs in that time window). According to the Belgian guidelines, pregnant women should receive an influenza vaccine during the second or third trimester of their pregnancy, implying the average delivery date of pregnant vaccine recipients is in calendar week 7 (assuming uniformly distributed deliveries over the year and vaccination in calendar week 47). It is assumed that when the pregnant mother dies due to influenza, so does the foetus. Therefore, to account for fatalities in the period leading up to calendar week 7, the discounted expected life years lost of both the mother and her unborn child are summed to calculate the associated cost-effectiveness ratios. From calendar week 7 until week 25, infants can be assumed to be exposed to an autonomous risk of acquiring an influenza infection (one third of the annual attack rate in the infant ( $<1$ year) age category). Within that period we foresee potential transferred vaccine-induced immunity from mother to child. Since the extent to which an immune response may translate into clinical protection is not yet demonstrated for our setting [23], we vary the factor by which vaccine efficacy is transferred from mother to child from $0 \%$ over $50 \%$ to $100 \%$ in sensitivity analysis. We ignore any separate health or cost consequences for the infants due to influenza-related deaths in mothers in the period after birth. Furthermore, we assume identical probabilities for influenza-related hospitalisation and death of the mother before and after giving birth. 
Finally the occurrence of multiple pregnancies has not been accounted for, since they only make up a small part of the total number of pregnancies.

The health outcomes for secondary symptomatic influenza infections amongst patients in contact with health care workers are calculated in the same manner as those for primary infections.

\section{Data sources and input parameters}

Table 1 contains all input parameters by risk group. In this subsection, we provide some background and clarification for these parameters.

The choice of age groups of people with underlying illnesses and patients in contact with HCWs is based on the available input data and on plausible options for vaccination. Patients in contact with HCWs are conservatively assumed to have the same characteristics (hospitalisation costs, hospitalisation and death rates, etc.) as the general population of the same age class. We limited the analysis to 50 year olds.

The number of yearly influenza-related hospitalisations and fatalities were estimated by applying an attributable fraction for influenza to reported influenza and pneumonia hospitalisations and fatalities. This attributable fraction was obtained by regressing weekly counts of influenza and pneumonia admissions and deaths on the weekly numbers of laboratory confirmed cases of respiratory pathogens that may cause influenza-like-illness or pneumonia (influenza (A and B), S. pneumoniae, adenovirus, respiratory syncytial virus, $m$. pneumoniae, parainfluenza, and haemophilus), population size, holiday and school term indicators. Details of this regression analysis are described elsewhere [3].

Cost-effectiveness was only assessed for increased uptake of the trivalent inactivated influenza vaccine (TIV), up to 2013 the only influenza vaccine type available in Belgium, and reimbursed for pregnant women, HCWs and people with underlying illnesses (amongst other risk groups). TIV provides moderate protection against outpatient virologically confirmed influenza with a pooled vaccine efficacy of $59 \%$ [95\% Cl 51\%-67\%] [17]. This estimate was used irrespective of age or risk class, because there is currently no evidence suggesting differences according to such characteristics $[1,3,17]$.

\section{Uncertainty, variable importance and sensitivity analysis}

Where appropriate, uncertainty around the input parameters was specified as probability distributions (Table 1, [24]). For the hospitalisation and case-fatality ratios, the number of successes and the number of failures from the beta distribution are based on the predictions obtained from different selected "best" regression models (see above). Model uncertainty was taken into account by randomizing with equal probability between selected regression models for the different outcome measures. To assess the uncertainty of the cost-effectiveness results, we conducted Monte-Carlo sampling with 10,000 draws taken from the joint input distribution, assuming independence of the uncertain input variables (i.e. probabilistic sensitivity analysis).

The relative influence of each of the uncertain parameters was investigated by fitting multiple linear regression models with as covariates all standardized uncertain input variables and as response the incremental costs, the incremental QALYs gained and the net benefits. The net benefit was calculated by 
subtracting the incremental costs from the QALYs gained valued at $€ 35,000$ per QALY. In Belgium there is no official willingness to pay threshold to obtain gains in (quality-adjusted) life years, but $€ 35,000$ is about the Gross Domestic Product per capita. The amount of GDP per capita has been put forward by the World Health Organization as representing the costs per QALY gained of a 'very cost-effective' strategy [25]. The larger the absolute value of the regression coefficients, the more important the uncertain parameter is in determining the response (incremental costs, QALYs and net benefits).

Probabilistic sensitivity analysis was repeated for different key model assumptions regarding clinical protection against influenza transferred from mother to child, the number of influenza cases caused in patients through contacts with health care workers, and life expectancy of people with underlying illnesses relative to that of the general population. An important question regarding implementation is whether we can assume zero marginal administration costs for vaccinating pregnant women or HCWs, or whether an additional GP visit will be charged for these acts. Since this was unknown to the Belgian program managers, both these options were evaluated.

\section{Results}

\section{Pregnant women}

The cost-effectiveness of increasing vaccine uptake in $2^{\text {nd }}$ or $3^{\text {rd }}$ term pregnant women depends on the assumed vaccine administration cost and the degree of vaccine protection indirectly inferred to the newborn child. Increasing vaccine uptake is very likely to be cost-effective when there are no marginal administration costs, or when these remain substantially lower than the current price for a GP consultation. At marginal administration costs of $1 \mathrm{GP}$ consult (€23.32), seasonal influenza vaccination of pregnant women would only be cost-effective, if indirectly transferred vaccine protection to the child is high (i.e. $100 \%$ in Figure 2). Figure S1 (in supplementary material) shows the variable importance, indicating that the case-fatality ratio of the mother, vaccine efficacy and QALY loss are all influential. Ignoring the life years lost due to the death of a foetus only has a minor impact on the cost-effectiveness (median ICER of $€ 6,706$ instead of $€ 6,616$ per QALY gained). With a per-season median of 26 versus 3 hospitalisations prevented, the incremental health gains of the program are larger for the neonates than for the pregnant women, respectively (see Table 2). The larger scope for prevented hospitalisations and deaths in neonates is due to the high risks for neonates afflicted by ILI (mean proportion hospitalised $2.92 \%$, based on the $0-4$ year old age group).

\section{Health care workers}

Also for HCWs, vaccine administration costs have a large influence on the cost-effectiveness of influenza vaccination, as well as the extent of indirect protection conferred to patients. That is, the assumed number of secondary symptomatic influenza infections among patients caused by an influenza case in the HCWs is influential. At zero marginal administration costs (i.e. vaccination during a routine medical visit or through occupational health doctor), increased influenza vaccination of active HCWs is likely to be cost-effective, even without accounting for secondary influenza cases (median ICER: €24,103 per QALY gained; 95\% ICER range: €16,421-€36,355; see Table S1 in Supplementary material). If we assume 
at least one secondary symptomatic influenza infection in the elderly patients above 75 years of age per

178 symptomatic infection in the HCWs the program becomes even cost-saving.

179 At marginal administration costs of one GP visit (€23.32), increased influenza vaccine uptake in HCWs 180 can be considered cost-effective, only if at least one secondary symptomatic influenza infection in 181 patients older than 64 is assumed per 3 primary symptomatic infections in the HCWs. Alternatively, at 182 least one secondary influenza case in persons aged 50-64 per primary case in HCWs can compensate for 183 these marginal administration costs (see Figure 3, Table S1 in Supplementary material).

184 Probabilistic sensitivity analysis, assuming one secondary symptomatic influenza infection per 185 symptomatic infection in the target group, reveals that the uncertainties around the case-fatality ratio 186 for secondary cases and the vaccine efficacy exert the highest relative influence on QALYs gained and 187 consequently on the net benefits (see Figure S2 in supplementary material). This finding holds for the different age groups of secondary cases.

We additionally investigated splitting up the group of HCWs according to age. Observed changes in ICER values are minor, since differences in input variables between HCW age groups are small.

Increasing vaccine uptake in people with underlying illnesses is cost-effective for persons aged 50 and older, for all life expectancies considered (Figure 4, Table 2). Also for younger persons, it is likely to be cost-effective for most combinations of uncertain parameters and life expectancies. The ICERs become less favourable when life expectancy of younger persons with underlying diseases is assumed to be only $30 \%$ of that of the general population of the same age group, and for small values of case-fatality ratios. Indeed, the uncertainty around the case-fatality ratio and to a lesser extent around vaccine efficacy are the most influential for all age groups, with the case fatality ratio being more influential in younger age groups. (Figure S3 in Supplementary material)

200 For these youngest age groups ( $<50$ years), we calculated the maximum marginal vaccination costs 201 (vaccine price and administration costs) such that the $95^{\text {th }}$ percentile of the ICER distributions falls below $202 € 35,000$. For children with underlying illness below 15 years of age, these maximum costs would be $203 € 20.44$ and $€ 7.57$, assuming their life expectancy was $50 \%$ and $30 \%$, respectively, of that of an average 204 child below 15 years of age. For the age group 15-49, such a maximum amount cannot be found using 205 the same assumptions for life expectancy (i.e. at zero marginal costs the $95^{\text {th }}$ percentile is above $206 € 35,000)$. 
For pregnant women, we found increased influenza vaccine uptake to be particularly cost-effective (median ICER < $€ 10,000$ per QALY gained). This result is similar to that of Jit et al. [6], when assuming identical administration costs. Jit et al did not attribute life years lost to fetal death, but used a higher overall vaccine efficacy estimate.

Also for elderly with underlying illness (65+), increased vaccine uptake yielded generally acceptable costeffectiveness. This contrasts with the few other studies for this target group (summarized in de Waere et al. [26]), mainly because we used a more favorable rapport between vaccine efficacy and occurrence of preventable disease. Cost-effectiveness fundamentally depends on relating vaccine efficacy on appropriate outcomes to reliable estimates of the occurrence of such outcomes in the context of the envisaged target group, for which we used the most specific, soundest and latest evidence [17, 27].

Ours is one of the few studies to evaluate the cost-effectiveness of influenza vaccination in HCWs [27]. We demonstrated that the cost-effectiveness of vaccinating HCWs depends strongly on the assumed number of secondary symptomatic influenza infections prevented in patients they contact, as well as these patients' ages and vulnerability to influenza. Up to now only Chicaiza-Becerra et al. [11] included such patient benefits. They found vaccination of Colombian HCWs who care for cancer patients, to be cost saving. Some of the studies not accounting for patient benefits, also reported favourable results [8, $10,28]$. Furthermore, there is empirical evidence to show that vaccination of HCWs might be more effective in preventing disease and death in the elderly in long-term care, than vaccinating these elderly patients directly $[19,20]$. These results are likely to be generalizable to HCWs making contact with other vulnerable groups such as people living in institutions and persons with severe underlying illnesses.

Our findings are based on the currently available evidence on vaccine efficacy and disease burden in the specific risk groups, combined with plausible assumptions inferred from the literature. For instance, vaccine efficacy was assumed constant over the different age and risk groups considered here since the most recent authoritative trial review found no age difference (in <65 years of age, [17]) and more recent observational studies found similar efficacy across risk groups [29-32]. Clearly, if future research would show vaccine efficacy to be lower in elderly with underlying illnesses, the cost-effectiveness of their vaccination would become less attractive. Better knowledge of vaccine efficacy would strongly reduce uncertainty in all presented cost-effectiveness results, because it remains a main source of uncertainty (see large impact of vaccine efficacy on the net benefit in Figure S1 in supplementary material), together with the case-fatality and hospitalisation ratios.

The basic structure of our decision-analytic model is rather conservative. Firstly, for pregnant women and people with underlying illnesses, herd immunity was not accounted for. Indeed, for these target groups herd immunity is likely to be negligible, because they are not core transmitter groups in the general population or in specific settings. Secondly, we assumed the vaccine would only protect for one season against the circulating strains. However, it seems plausible that some vaccine recipients would enjoy some residual protection into the next season, and that therefore this is also a conservative 
assumption. Thirdly, we opted for a mean approach for the relative timings of vaccination of pregnant women in relation to the onset of the influenza season and gestational age, based on previous seasons. However, previous studies found assumptions regarding these relative timings to be influential for the cost-effectiveness [6, 7]. Clearly, vaccination of second or third term pregnant women is more effective and cost-effective, if it can take place before or as early as possible in the flu season.

\section{Acknowledgments}

This study was commissioned and co-financed by the Health Care Knowledge Centre (KCE) of the Belgian Federal government. Adriaan Blommaert acknowledges support from the University of Antwerp concerted research action number 23405 (BOF-GOA); Joke Bilcke is supported by a postdoctoral grant from the Science Foundation Flanders (FWO); Yannick Vandendijck is supported by a doctoral grant of Hasselt University (BOF11D04FAEC). We also gratefully acknowledge financial support by the IAP Research Network P7/06 of the Belgian State (Belgian Science Policy).

We are grateful to dr. Benson Ogunjimi for reviewing diagnostic codes on underlying illnesses, to Nancy Thiry for performing the literature review on quality of life estimates, to France Vrijens and Carl Devos for support in the regression analysis and to the Scientific Institute of Public Health (ISP - WIV), the UZ Leuven Reference Laboratory for Streptococcus pneumoniae, the Technical Cell for the Minimal Clinical Data, the Wallonia-Brussels Federation, the Flemish Agency for Care and Health and the Brussels-Capital Health and Social Observatory for providing data for the regression analysis on admissions and deaths. This study benefited from discussions held within the context of KCE report 204, the expert committee of which included: Rik Baeten (VIGEZ), Johan Bots (Gemeenschappelijke Gemeenschapscommissie), Liesbeth Dejaegere (VIGEZ), Ann Malfroot (UZ Brussel), Daniel Reynders (SPF Santé Publique - FOD Volksgezondheid), Béatrice Swennen (Université Libre de Bruxelles), Isabelle Thomas (ISP - WIV), Geert Top (Vlaams Agentschap Zorg en Gezondheid), Patrick Tréfois (Question Santé), Yves Van Laethem (Centre Hospitalier Universitaire St. Pierre), Anne Vergison (Université Libre de Bruxelles), Françoise Wuillaume (ISP - WIV).

\section{Author contributions}

PB conceived the study. $A B$ developed and implemented the model. $G H, Y V, J B$ and PB provided input data. $A B$ performed and interpreted the analyses, with revisions by $P B, J B$ and $G H$. $A B, P B$ and JB wrote the manuscript, which $\mathrm{GH}$, JV and $\mathrm{NH}$ critically revised. All authors approved the final version of the manuscript

\section{Conflicts of interest}

The authors have no conflicts of interest to declare. 
280 Table 1: Input parameter values and distributions used for pregnant women, health care workers and people with underlying illnesses.

\begin{tabular}{|c|c|c|c|c|}
\hline \multirow[b]{2}{*}{ Parameter } & \multicolumn{3}{|l|}{ Value or distribution } & \multirow[b]{2}{*}{ Source } \\
\hline & Pregnant women $^{a}$ & Health Care Workers $^{a}$ & People with underlying illnesses & \\
\hline \multicolumn{5}{|c|}{ Vaccination program and vaccine characteristics } \\
\hline Size target group & 121,363 & 239,740 & $\begin{array}{l}117,473 \text { (0-14 years of age) } \\
407,613 \text { (15-49 years of age) } \\
320,672 \text { ( } 50-64 \text { years of age) } \\
559,788 \text { (over } 65 \text { years of age) }\end{array}$ & [1] \\
\hline Vaccine uptake $\left(\mathrm{P}_{\mathrm{vac}}\right)$ & $\begin{array}{l}0.50 \text { increased uptake scenario } \\
0 \text { current uptake scenario } \\
\text { (assumed) }\end{array}$ & $\begin{array}{l}0.50 \text { increased uptake scenario } \\
0.35 \text { current uptake scenario }\end{array}$ & $\begin{array}{l}0.40 \text { increased uptake scenario } \\
0.20 \text { current uptake scenario }\end{array}$ & [1] \\
\hline $\begin{array}{l}\text { Fixed marginal cost } \\
\text { vaccination programme }\end{array}$ & \multicolumn{3}{|l|}{$€ 0$} & \\
\hline $\begin{array}{l}\text { Variable vaccination costs: } \\
\text { TIV per dose }\end{array}$ & \multicolumn{3}{|l|}{$€ 11.81$} & [33] \\
\hline $\begin{array}{l}\text { Variable administration cost } \\
\text { per dose (GP visit in Belgium) }\end{array}$ & $€ 0$ or $€ 23.32$ & $€ 0$ or $€ 23.32$ & $€ 23.32$ & {$[33]$} \\
\hline $\begin{array}{l}\text { Vaccine efficacy of the TIV } \\
\text { vaccine }(\varepsilon)\end{array}$ & \multicolumn{3}{|l|}{ Gaussian(mean=0.59; sd=0.04) } & [17] \\
\hline \multicolumn{5}{|l|}{ Epidemiological parameters } \\
\hline $\begin{array}{l}\text { Yearly attack rate of influenza } \\
\text { like illness (ILI) seeking } \\
\text { medical care }\left(\lambda_{\mathrm{ILL}}\right)\end{array}$ & \multicolumn{3}{|c|}{ Weighted average over the age distribution } & $\begin{array}{l}\text { The yearly attack rate for } \\
\text { patients with ILI seeking medical } \\
\text { care was obtained by dividing the } \\
\text { predicted number of ILI } \\
\text { infections, under current } \\
\text { vaccination coverage, from a } \\
\text { dynamic transmission model [3] } \\
\text { by the population size in that age } \\
\text { cohort. }\end{array}$ \\
\hline $\begin{array}{l}\text { The proportion of influenza } \\
\text { within the ILI cases seeking } \\
\text { medical care }\left(P_{\text {influ }}\right)\end{array}$ & $\begin{array}{ll}\text { - } & \text { Beta }(2,070 ; 2,075) \text { for } \\
\text { pregnant women } \\
\text { - } \\
\text { Beta }(132 ; 2,075) \text { for } \\
\text { neonates }\end{array}$ & $\operatorname{Beta}(2,070 ; 2,075)$ & $\begin{array}{l}-\operatorname{Beta}(751 ; 593)(0-14 \\
\text { years of age) } \\
\text { - } \quad \text { Beta }(2,070 ; 2,075)(15- \\
49 \text { years of age) }\end{array}$ & {$[3]$} \\
\hline
\end{tabular}




\begin{tabular}{|c|c|c|c|c|}
\hline & & & $\begin{array}{l} \\
64 \text { years of age) } \\
\text { years of age) }\end{array}$ & \\
\hline $\begin{array}{l}\text { The proportion of } \\
\text { symptomatic influenza cases } \\
\text { who do not seek medical } \\
\text { care: no GP visit, not } \\
\text { hospitalised. }\left(P_{\text {nomed }}\right)\end{array}$ & \multicolumn{3}{|l|}{$\operatorname{Beta}(1,107 ; 1,143)$} & [3] \\
\hline $\begin{array}{l}\text { The hospitalisation rate of } \\
\text { influenza cases seeking } \\
\text { medical care }(\tau)\end{array}$ & $\begin{array}{l}\text { We randomize with equal } \\
\text { probability between } 3 \text { scenarios: } \\
\left.\text { - } \quad \text { Beta(7, DENOM }{ }^{b}-7\right) \\
\text { - } \quad \operatorname{Beta}\left(11, \text { DENOM }^{b}-11\right) \\
\text { - } \quad \operatorname{Beta}\left(15, \text { DENOM }^{b}-15\right)\end{array}$ & $\begin{array}{l}\text { We randomize with equal } \\
\text { probability between } 2 \text { scenarios: } \\
\begin{array}{l}\text { Beta(18, DENOM } \\
\text { - }-18)\end{array} \\
\text { Beta(55, DENOM }-1.3)\end{array}$ & 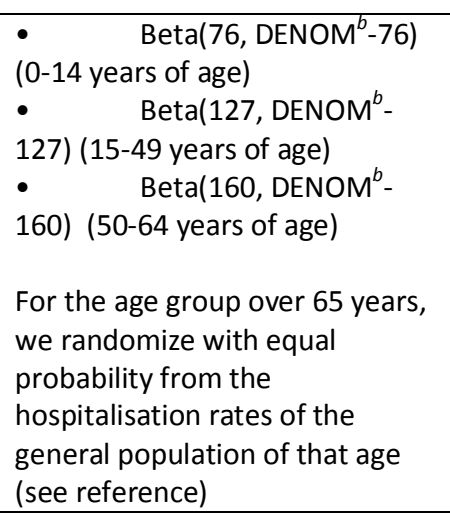 & [3] \\
\hline $\begin{array}{l}\text { The case fatality ratio of } \\
\text { influenza cases seeking } \\
\text { medical care }(\mu)\end{array}$ & $\begin{array}{l}\text { For pregnant women we } \\
\text { randomize between } 2 \text { scenarios } \\
\text { Beta(0.1, DENOM }-0.1) \\
\left.\text { Beta(0.2, DENOM }{ }^{c}-0.2\right) \\
\text { For neonates we randomize } \\
\text { between model predictions of the } \\
\text { general (hospitalised) population } \\
\text { between } 0-5 \text { years of age }{ }^{d}\end{array}$ & $\begin{array}{l}\text { For HCW, we randomize between } \\
2 \text { scenarios: } \\
\text { - } \quad \operatorname{Beta}\left(0.6, \text { DENOM }^{b}-0.6\right) \\
\left.\text { Beta(1.3, DENOM }{ }^{b}-1.3\right) \\
\text { We randomize between models } \\
\text { for the elderly (hospitalised) } \\
\text { population }{ }^{c}\end{array}$ & $\begin{array}{l}\left.\text { - Beta(2, DENOM }{ }^{b}-2\right)(0- \\
14 \text { years of age) } \\
\left.\text { Beta(8, DENOM }{ }^{b}-8\right) \\
(15-49 \text { years of age) } \\
\text { (50-64 years of age) } \\
\\
\text { For the age group over } 65 \text { years } \\
\text { we randomize from the case } \\
\text { fatality ratios of the general } \\
\text { (hospitalised) population of that } \\
\text { age }^{c}\end{array}$ & [3] \\
\hline \multicolumn{5}{|c|}{ Outcomes: quality of life and life expectancy } \\
\hline $\begin{array}{l}\text { QALY loss for an ambulatory } \\
\text { patient }\end{array}$ & \multicolumn{3}{|c|}{$\begin{array}{l}0.0071 \text { (sampling from } 8 \text { Gaussian distributions: } 7 \text { days for which VAS scores were measured + number of } \\
\text { days with symptoms) }\end{array}$} & [34], [3] \\
\hline
\end{tabular}




\begin{tabular}{|c|c|c|c|c|}
\hline $\begin{array}{l}\text { Duration of symptoms for an } \\
\text { ambulatory patient }\end{array}$ & \multicolumn{3}{|c|}{ Gaussian (mean=6.43; sd=0.14) } & [3] \\
\hline $\begin{array}{l}\text { Duration of symptoms for a } \\
\text { hospitalised patient }\end{array}$ & \multicolumn{3}{|c|}{ Gaussian $($ mean=8.5; sd=1.04) } & [3] \\
\hline $\begin{array}{l}\text { Duration of symptoms for a } \\
\text { person not seeking medical } \\
\text { care }\end{array}$ & \multicolumn{3}{|c|}{ Gaussian (mean=5.51; sd=0.14) } & [3] \\
\hline $\begin{array}{l}\text { QALY loss for a hospitalised } \\
\text { patient }\end{array}$ & \multicolumn{3}{|c|}{$\begin{array}{l}\text { QALY loss ambulatory patient * ratio duration of symptoms hospitalised patient and duration of symptoms } \\
\text { ambulatory patient }\end{array}$} & $\begin{array}{l}\text { Assuming average QALY loss for a } \\
\text { day with influenza does not differ } \\
\text { between ambulatory patients, } \\
\text { hospitalised patients and persons }\end{array}$ \\
\hline $\begin{array}{l}\text { QALY loss for a person not } \\
\text { seeking medical care }\end{array}$ & \multicolumn{3}{|c|}{$\begin{array}{l}\text { QALY loss ambulatory patient * ratio duration symptoms person not seeking medical care and duration of } \\
\text { symptoms ambulatory patient }\end{array}$} & \\
\hline Life expectancy & as a function of age & as a function of age & $\begin{array}{l}\text { as a function of age multiplied } \\
\text { with a factor } 1 \text { or } 0.5 \text { or } 0.3 \text { to } \\
\text { investigate the influence of } \\
\text { shorter life expectancy due to } \\
\text { underlying illnesses }\end{array}$ & [3] \\
\hline \multicolumn{5}{|c|}{$\begin{array}{l}\text { Outcomes: Costs: } \\
\text { We use a single randomization parameter for the following } 3 \text { cost categories, to randomize between the highest and lowest costs with equal probability }\end{array}$} \\
\hline \multirow{2}{*}{$\begin{array}{l}\text { Out-of-hospital costs for a } \\
\text { hospitalised patient }\end{array}$} & \multicolumn{3}{|c|}{ lowest unit costs: Gaussian(mean=€119.65, sd=€17.69) } & [3] \\
\hline & \multicolumn{3}{|c|}{ highest unit costs: Gaussian(mean=€139.94, sd=€20.19) } & [3] \\
\hline \multirow{2}{*}{$\begin{array}{l}\text { Cost for an ambulatory } \\
\text { patient (i.e. consulting GP) } \\
\text { (no difference between ILI } \\
\text { and influenza) }\end{array}$} & \multicolumn{3}{|c|}{ lowest unit costs: Gaussian(mean=€51.04, sd=€1.18) } & [3] \\
\hline & \multicolumn{3}{|c|}{ highest unit costs: Gaussian(mean=€63.8, sd=€1.34) } & [3] \\
\hline $\begin{array}{l}\text { Cost for a person with ILI not } \\
\text { seeking medical care }\end{array}$ & \multicolumn{3}{|c|}{ lowest unit costs: Gaussian (mean=€3.39, sd=€0.21) } & [3] \\
\hline
\end{tabular}




\begin{tabular}{|c|c|c|c|c|}
\hline & \multicolumn{3}{|c|}{ highest unit costs: Gaussian (mean=€7.17, $s \mathrm{~d}=€ 0.37$ ) } & \multirow{2}{*}{$\begin{array}{l}\text { [3] } \\
\text { [3] }\end{array}$} \\
\hline $\begin{array}{l}\text { In-hospital cost for a } \\
\text { hospitalised patient }{ }^{d}\end{array}$ & 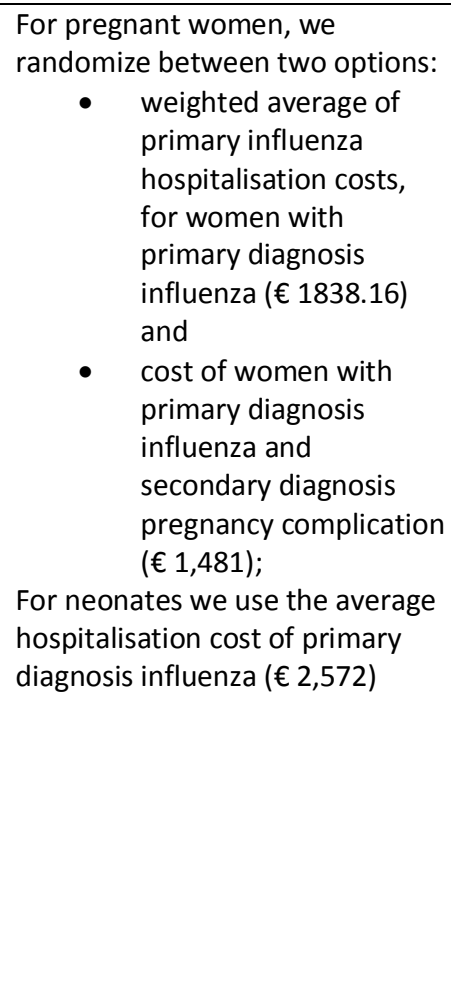 & 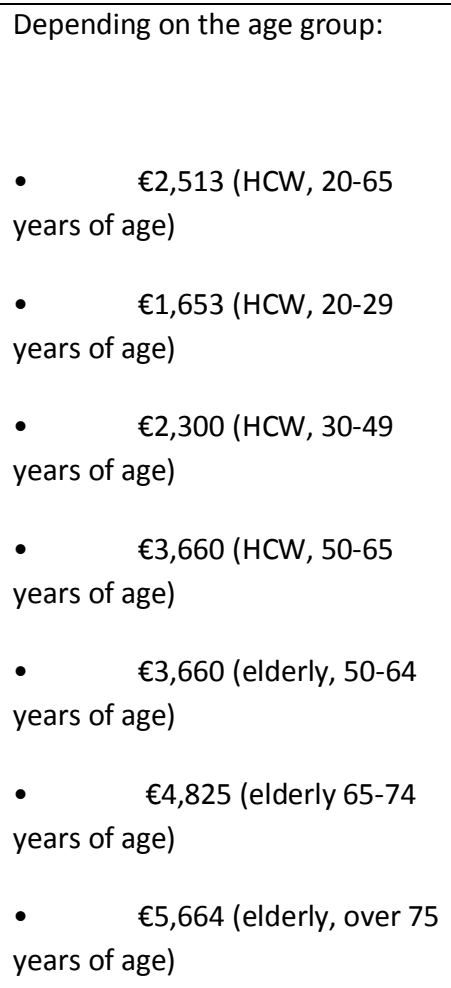 & 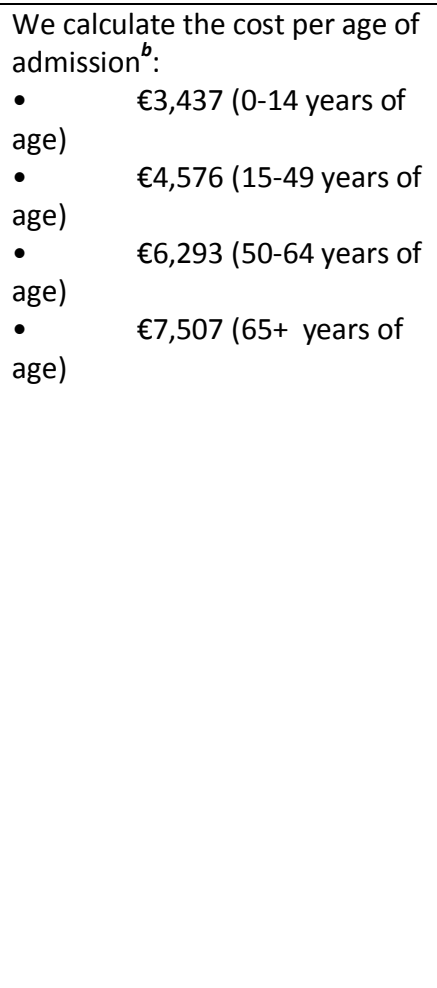 & \\
\hline \multicolumn{5}{|l|}{ Discount rates } \\
\hline Discount rate for costs & \multicolumn{3}{|l|}{0.03} & [22] \\
\hline $\begin{array}{l}\text { Discount rate for health } \\
\text { effects }\end{array}$ & \multicolumn{3}{|l|}{0.015} & [22] \\
\hline \multicolumn{5}{|c|}{ Specific factors for the pregnancy model } \\
\hline $\begin{array}{l}\text { Proportion of attack rate }\left(\lambda_{\mathrm{ILL}}\right) \\
\text { exposure during pregnancy } \\
\text { and during the period of } \\
\text { vaccine protection for the }\end{array}$ & 0.84 & & - & See attack rate $\left(\lambda_{\mathrm{IL}}\right)$ \\
\hline
\end{tabular}




\begin{tabular}{|c|c|c|c|c|}
\hline $\begin{array}{l}\text { cohort giving birth, on } \\
\text { average, on } 15 \text { th February. } \\
\text { This period is defined as } \\
\text { week } 51 \text {-week } 25\end{array}$ & & & & \\
\hline $\begin{array}{l}\text { In mothers who acquire } \\
\text { influenza and die during } \\
\text { pregnancy, the proportion of } \\
\text { neonates who are not yet } \\
\text { born. (Cases week } 51 \text {-week } 7 \\
\text { of the mother/ cases week } \\
51-25 \text { for women) }\end{array}$ & 0.58 & - & - & See attack rate $\left(\lambda_{\mid \mathrm{ILI}}\right)$ \\
\hline $\begin{array}{l}\text { Proportion of the attack rate } \\
\left(\lambda_{\mid L I)} \text { applicable to neonates }\right. \\
\text { after they are born. (week 8- } \\
25 \text { ) }\end{array}$ & 0.33 & - & - & See attack rate $\left(\lambda_{\mathrm{ILI}}\right)$ \\
\hline
\end{tabular}

Belgium (20-65 years), but narrower age categories (20-30; 30-50 and 50-65 years of age) are used in sensitivity analyses.

${ }^{b}$ DENOM refers to the denominator of the case fatality ratio and hospital rate, and has the meaning of the number of Influenza cases seeking medical care sampled from a run of the static model (see Figure 1) with the current uptake scenario vaccination coverage. Working with model based versus observed denominators had an ignorable impact on the cost-effectiveness.

${ }^{b}$ Hospitalisation rates and case fatality ratios of an age class of the general population were calculated by applying the attributable fraction of influenza derived from regression models to the observed number of influenza and pneumonia per observed influenza cases in the target group.

${ }^{d}$ People with underlying illnesses were identified by looking for following underlying ICD-9 diagnostic codes (http://icd9.chrisendres.com): asthma (493; V17.5), cardiovascular disease $(989.1,402.01,402.11,402.91,404.01,404.03,404.11,404.13,404.91,404.93,428,413,412,410$, 411, 414, 420, 422), chronic obstructive pulmonary disorder (490492), diabetes (249, 250, V18.0, V77.1, 253.5, 588.1), HIV (042), hypertension (401-405, 997.91, 459.3) and stroke (430-438, 342).

${ }^{e}$ Direct costs for a deceased person are implicitly accounted for in the costs for medication, GP visit and hospitalisation, as the sum of these 3 relates to the total number of influenza cases (including those who die from influenza)

TIV: Trivalent Inactivated Influenza Vaccine; HCW: health care workers; CFR: case-fatality ratio; ILI: Influenza like illness

Age specific parameters such as the attack rate, hospitalisation costs and life expectancy were summarized by taking averages, weighted by the age distribution in the general population in 2011. For pregnant women, the weights were based on the frequency of live births by age of the mother. 
Table 2: Incremental direct costs, Quality-Adjusted Life-years (QALYs) and cost-effectiveness ratio (ICER) of increased seasonal influenza vaccination uptake in different target groups. Results of 10,000 simulations, presented as median (mean) [95\% range] (price level 2011)

\begin{tabular}{|c|c|c|c|c|c|c|}
\hline & \multirow{2}{*}{$\begin{array}{l}\text { Pregnant women }{ }^{a} \\
\text { (121,363 persons) }\end{array}$} & \multirow{2}{*}{$\begin{array}{l}\text { Health care } \\
\text { workers } \\
(239,740 \text { persons })\end{array}$} & \multicolumn{4}{|c|}{ People with underlying illnesses ${ }^{c}$} \\
\hline & & & $\begin{array}{l}0-14 \text { years of age } \\
\text { (117,473 persons) }\end{array}$ & $\begin{array}{l}15-49 \text { years of age } \\
\text { (407,613 persons) }\end{array}$ & $\begin{array}{l}\text { 50-64 years of age } \\
\text { (320,672 persons) }\end{array}$ & $\begin{array}{l}\text { Over } 65 \text { years of age } \\
\text { ( } 559,788 \text { persons) }\end{array}$ \\
\hline Program coverage & From $0 \%$ to $50 \%$ & From $35 \%$ to $50 \%$ & From $20 \%$ to $40 \%$ & From $20 \%$ to $40 \%$ & From $20 \%$ to $40 \%$ & From $20 \%$ to $40 \%$ \\
\hline $\begin{array}{l}\text { Assumed marginal } \\
\text { administration costs }\end{array}$ & $€ 0$ & $€ 0$ & $€ 23.32$ & $€ 23.32$ & $€ 23.32$ & $€ 23.32$ \\
\hline $\begin{array}{l}\text { hospitalisations } \\
\text { prevented - neonate }\end{array}$ & $26(26)[20-33]$ & - & - & - & - & - \\
\hline $\begin{array}{l}\text { hospitalisations } \\
\text { prevented - target } \\
\text { group }\end{array}$ & $3(3)[1-5]$ & $3(4)[1-8]$ & $10(10)$ [8-13] & 17 (17) [13-21] & $21(21)$ [17-26] & 156 (166) [99-249] \\
\hline $\begin{array}{l}\text { Deaths prevented - } \\
\text { neonate }\end{array}$ & $\begin{array}{l}0.07(0.09)[0.04- \\
0.33]\end{array}$ & - & - & - & - & - \\
\hline $\begin{array}{l}\text { Deaths prevented - } \\
\text { target group }\end{array}$ & $\begin{array}{l}0.00(0.04)[0.00- \\
0.33]\end{array}$ & $\begin{array}{l}0.07(0.10)[0.00- \\
0.42]\end{array}$ & $\begin{array}{l}0.23(0.27)[0.03- \\
0.77]\end{array}$ & $1.02(1.06)[0.45-1.93]$ & $3.96(4.02)[2.63-5.77]$ & $\begin{array}{l}42.41(43.53) \text { [31.10- } \\
58.71]\end{array}$ \\
\hline $\begin{array}{l}\text { Incremental direct } \\
\text { costs }\end{array}$ & $\begin{array}{l}€ 385,978 \\
(€ 383,962) \\
{[€ 309,787-} \\
€ 450,365]\end{array}$ & $\begin{array}{l}€ 709,703 \\
(€ 709,133) \\
{[€ 673,983-} \\
€ 740,952]\end{array}$ & $\begin{array}{l}€ 689,687 \\
(€ 689,189) \\
{[€ 658,694-} \\
€ 716,877]\end{array}$ & $\begin{array}{l}€ 2,476,027 \\
(€ 2,473,748) \\
{[€ 2,388,545-} \\
€ 2,552,104]\end{array}$ & $\begin{array}{l}€ 1,902,263 \\
(€ 1,901,102) \\
{[€ 1,830,151-} \\
€ 1,967,352]\end{array}$ & $\begin{array}{l}€ 2,587,383(€ 2,513,987) \\
{[€ 1,857,678-€ 3,044,346]}\end{array}$ \\
\hline Incremental QALYs & $58(59)[40-85]$ & $29(30)[20-43]$ & $31(33)[20-56]$ & 100 (101) [70-139] & 132 (133) [97-176] & 518 (529) [382-708] \\
\hline ICER & $\begin{array}{l}€ 6,616(€ 6,763) \\
{[€ 4,097-€ 10,345]}\end{array}$ & $\begin{array}{l}€ 24,096(€ 24,595) \\
{[€ 16,442-€ 36,342]}\end{array}$ & $\begin{array}{l}€ 22,008(€ 22,596) \\
{[€ 12,180-€ 36,574]}\end{array}$ & $\begin{array}{l}€ 24,768(€ 25,278) \\
{[€ 17,623-€ 35,725]}\end{array}$ & $\begin{array}{l}€ 14,378(€ 14,610) \\
{[€ 10,627-€ 20,005]}\end{array}$ & $\begin{array}{l}€ 4,784(€ 4,932)[€ 2,797- \\
€ 7,607]\end{array}$ \\
\hline
\end{tabular}

301 ' Assuming the same life expectancy as the general population of the same age 


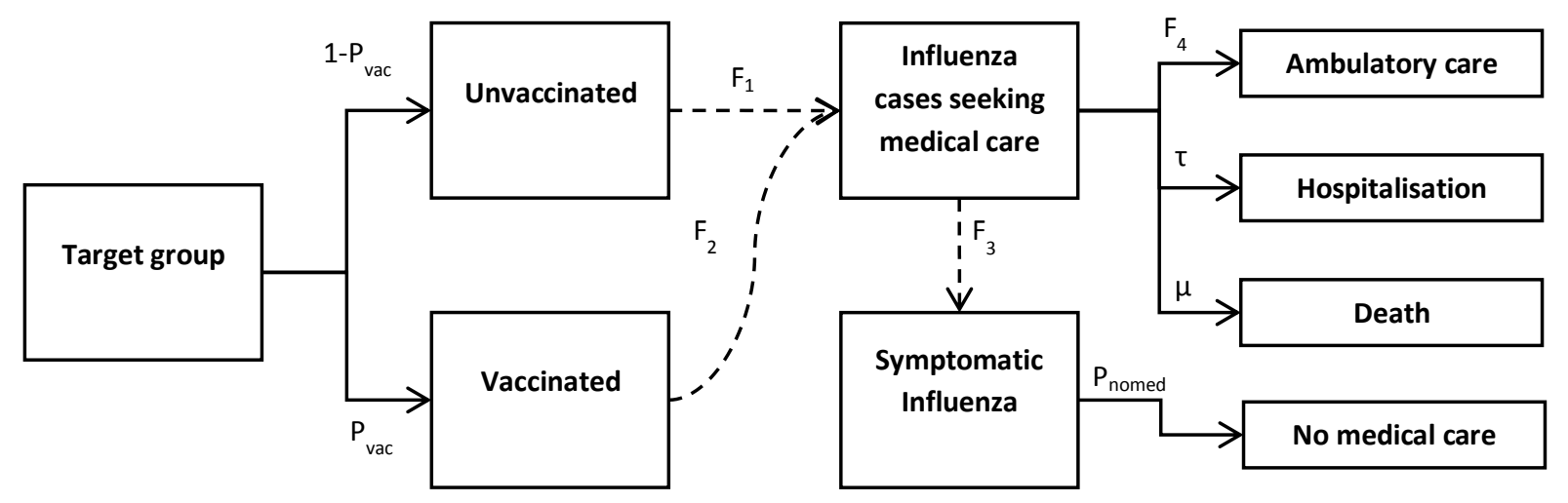

Full arrows indicate the causal structure of the model. Dashed arrows indicate how the group sizes were calculated, when it is different from the causal structure, and how the sizes of the different groups were calculated using the input data available in Table $1 . F_{1}=\lambda_{\mid L I} * P_{\text {influ }} ; F_{2}=F_{1} *(1-\varepsilon) ; F_{3}=1 /\left(1-P_{\text {nomed }}\right) ; F_{4}=$ $1-\mu-\tau ; P_{\mathrm{vac}}$ is the vaccination coverage of the target group; $\lambda_{\mathrm{IL}}$ is the yearly attack rate of influenza like illness (ILI) for which medical care is sought; $P_{\text {influ }}$ is the proportion of influenza relative to the ILI cases seeking medical care; $\varepsilon$ is the vaccine efficacy against influenza; $\tau$ is the influenza hospitalisation rate, $\mu$ the influenza death rate and $P_{\text {nomed }}$ is the proportion of symptomatic influenza cases not seeking medical care (see also Table 1 ). 
Figure 2: Cost-effectiveness acceptability curves for vaccinating $50 \%$ versus $0 \%$ of $2^{\text {nd }}$ or $3^{\text {rd }}$ term pregnant women while varying the administration cost from

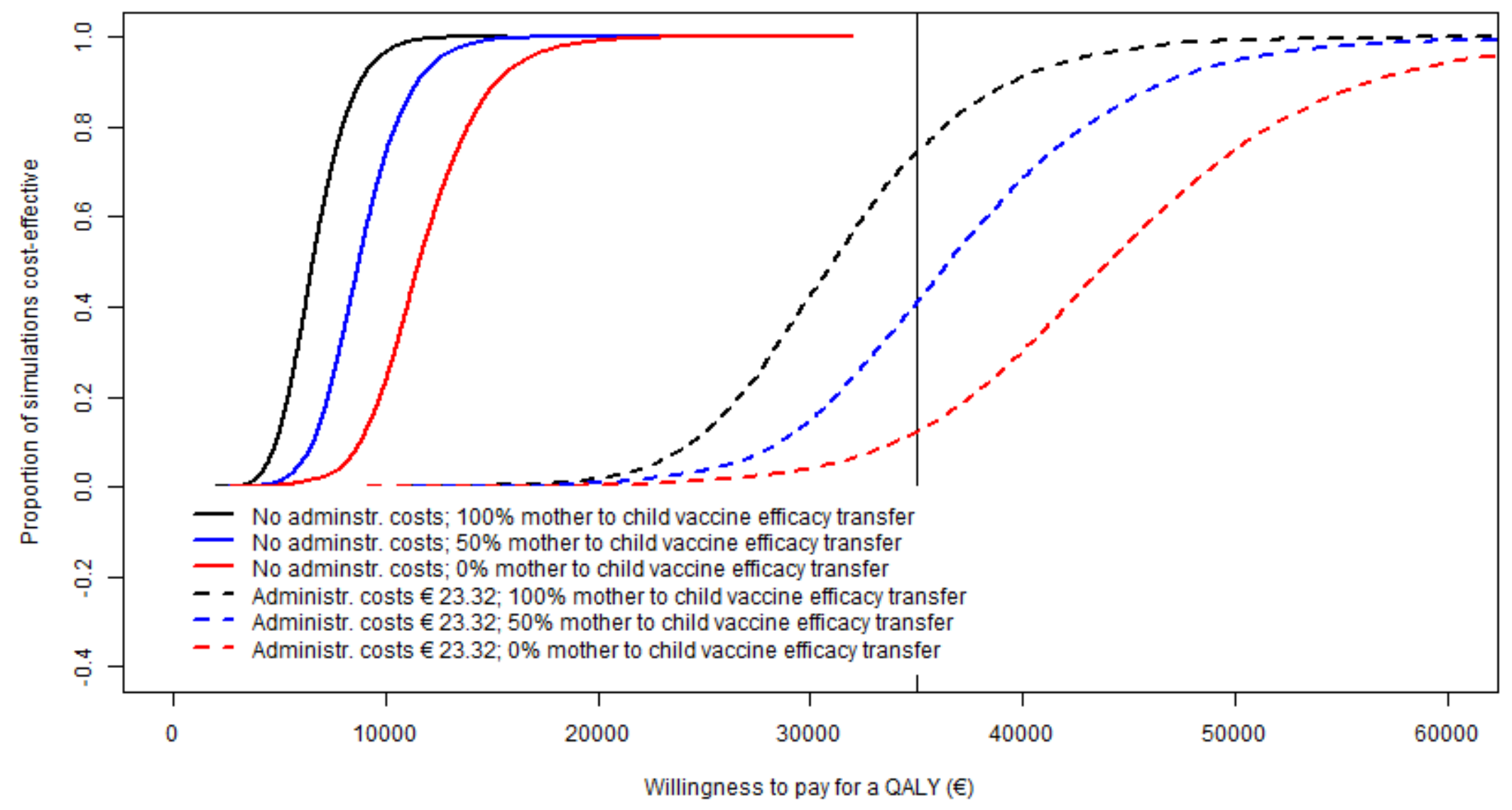


Figure 3: Cost-effectiveness acceptability curves for vaccinating $50 \%$ versus $35 \%$ of health care workers $20-65$ years of age, with varying numbers of secondary infections in elderly patient groups of various ages ("sec. inf. eld." In graph legend), assuming marginal administration costs of €23.32. The vertical bar indicates a willingness to pay for a Quality-Adjusted Life-Year (QALY) of €35,000.

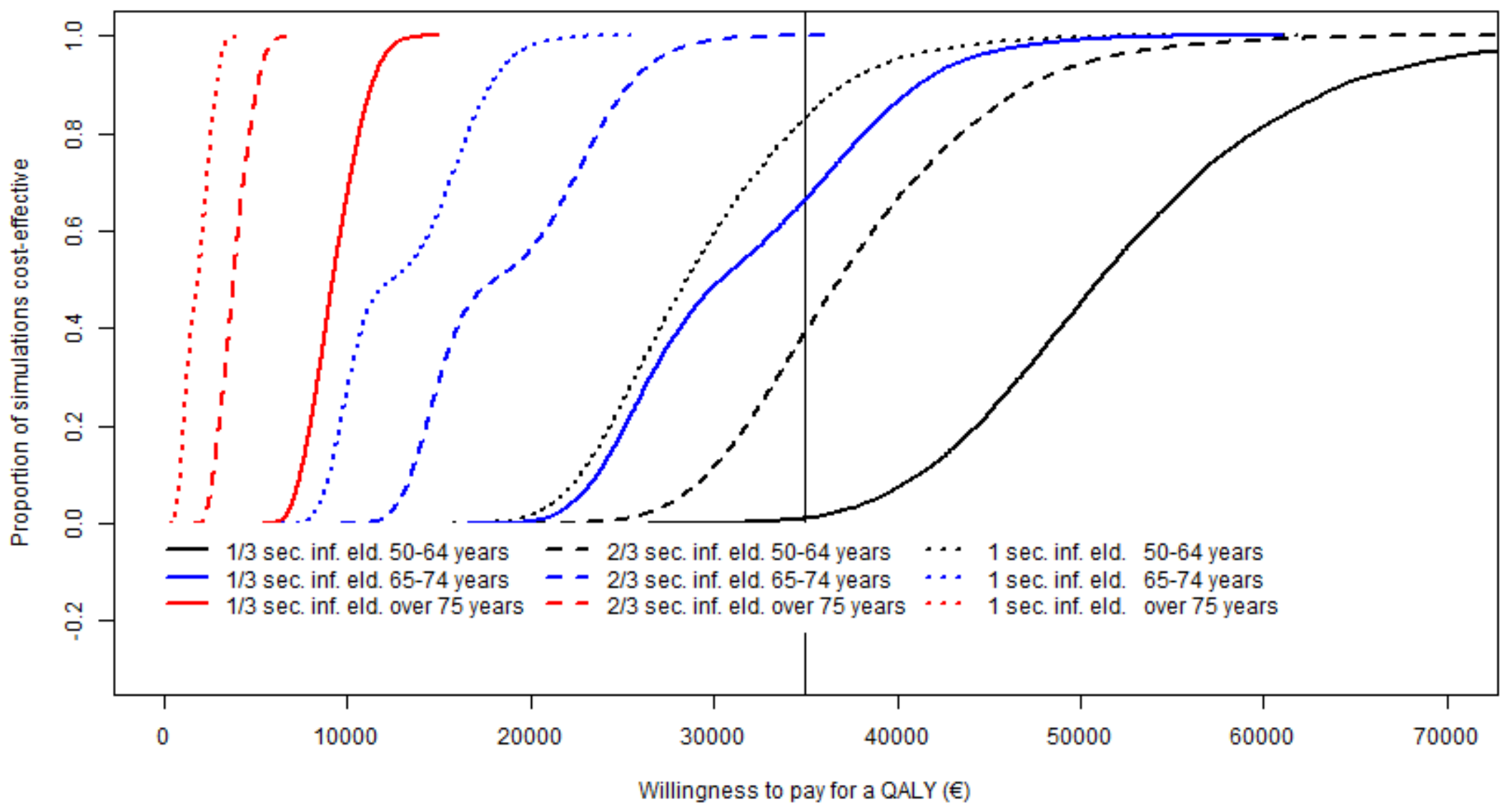




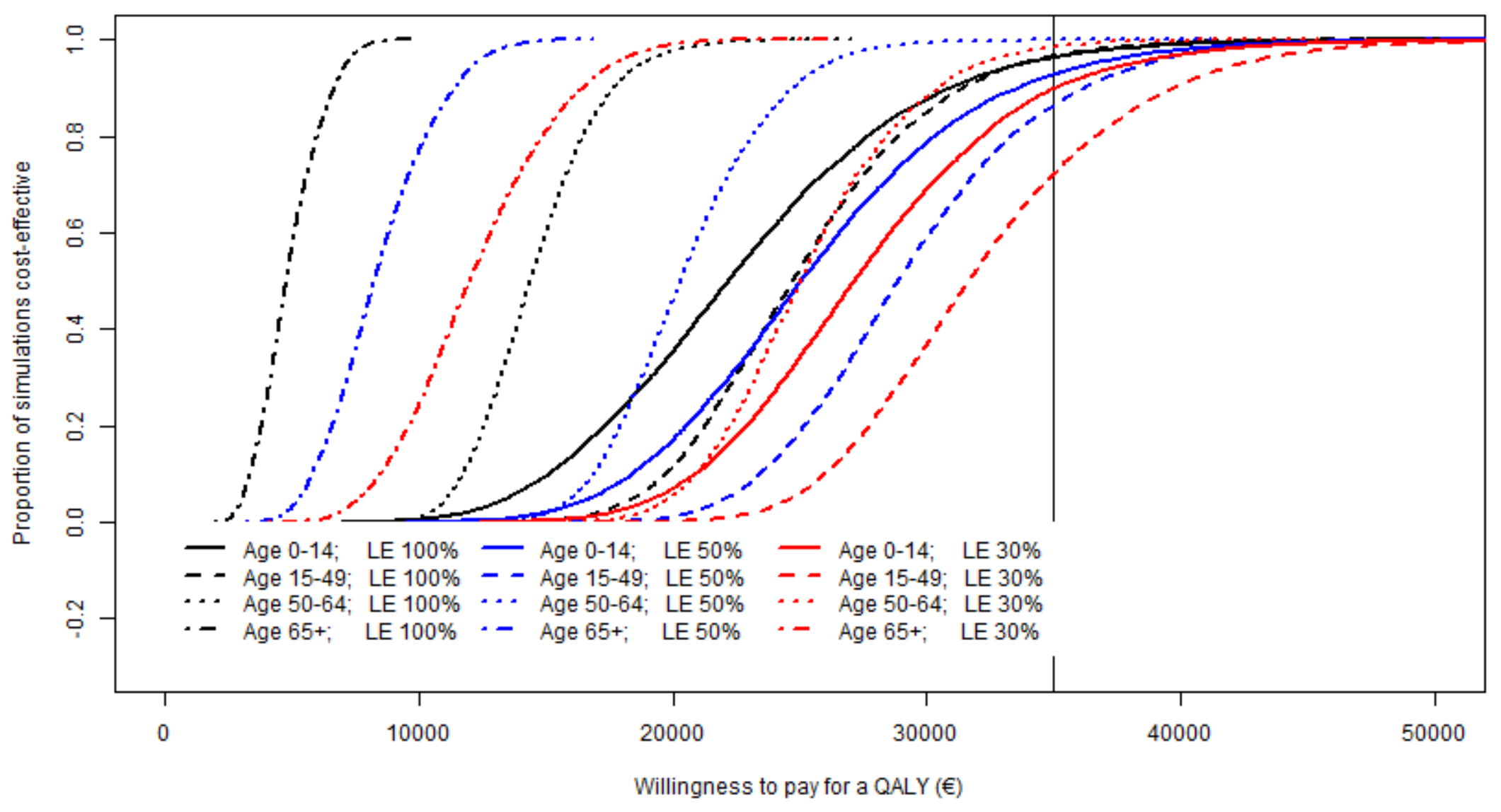


326 [1] Hanquet G, Jonckheer P, Vlayen J, Vrijens F, Thiry N, Beutels P. Seasonal influenza vaccination: 327 priority target groups - Part 1. Good Clinical Practice (GCP). Brussels: Belgian Health Care Knowledge 328 Centre (KCE). 2011;KCE Reports 162C. D/2011/10.273/45.

329 [2] Belgian Health Council. Vaccination contre la grippe saisonnière Saison hivernale 2010 - 2011. 330 Brussels: Belgian Health Council. 2010;September 2010. 8682.

331 [3] Beutels P, Vandendijck Y, Willem L, Goeyvaerts N, Blommaert A, Van Kerckhove K, et al. Seasonal 332 influenza vaccination: prioritizing children or other target groups? Part II: cost-effectiveness analysis. 333 Brussels: Belgian Health Care Knowledge Centre (KCE). 2013;KCE Reports 204S2. D/2013/10.273/47.

[4] Jefferson T. Influenza vaccination: policy versus evidence. BMJ. 2006;333:912-5.

[5] Beigi RH, Wiringa AE, Bailey RR, Assi T-M, Lee BY. Economic Value of Seasonal and Pandemic Influenza Vaccination during Pregnancy. Clinical Infectious Diseases. 2009;49:1784-92.

[6] Jit M, Cromer D, Baguelin M, Stowe J, Andrews N, Miller E. The cost-effectiveness of vaccinating pregnant women against seasonal influenza in England and Wales. Vaccine. 2010;29:115-22. [7] Myers ER, Misurski DA, Swamy GK. Influence of timing of seasonal influenza vaccination on effectiveness and cost-effectiveness in pregnancy. American Journal of Obstetrics and Gynecology. 2011;204:S128-S40.

[8] Festini F, Biermann KP, Neri S, Reali MF, de Martino M. Influenza vaccination of nurses in an Italian pediatric hospital: effects on absenteeism and on costs, factors associated with vaccine uptake and analysis of personal motivations. A prospective cohort study. Assist Inferm Ric. 2007;26:5-13.

[9] Dutheil F, Delaire P, Boudet G, Rouffiac K, Djeriri K, Souweine B, et al. [Cost/effectiveness comparison of the vaccine campaign and reduction of sick leave, after vaccination against influenza among the Clermont-Ferrand University Hospital staff]. Medecine et maladies infectieuses. 2008;38:567-73. [10] Colombo GL, Ferro A, Vinci M, Zordan M, Serra G. Cost-benefit analysis of influenza vaccination in a public healthcare unit. Therapeutics and clinical risk management. 2006;2:219-26.

[11] Chicaiza-Becerra LA, Garcia-Molina M, Ballesteros M, Gamboa O, Diaz J, Vega R. Economic evaluation of influenza vaccine applied to health personnel attending hospitalised oncological patients. Rev Salud Publica (Bogota). 2008;10:756-66.

[12] Abbott KC, Yuan CM, Lee JL. Nothing to sneeze at: efficacy and cost-effectiveness of the influenza vaccine in patients receiving long-term dialysis. American Journal of Kidney Diseases. 2011;57:651-3. [13] Lee BY, Stalter RM, Bacon KM, Tai JH, Bailey RR, Zimmer SM, et al. Cost-effectiveness of adjuvanted versus nonadjuvanted influenza vaccine in adult hemodialysis patients. American Journal of Kidney Diseases. 2011;57:724-32.

[14] Nosyk B, Sharif B, Sun H, Cooper C, Anis AH. The Cost-Effectiveness and Value of Information of Three Influenza Vaccination Dosing Strategies for Individuals with Human Immunodeficiency Virus. Plos One. 2011;6:e27059.

[15] Teufel RJ, Basco WT, Simpson KN. Cost effectiveness of an inpatient influenza immunization assessment and delivery program for children with asthma. J Hosp Med. 2008;3:134-41.

[16] Trogdon JG, Nurmagambetov TA, Thompson HF. The Economic Implications of Influenza Vaccination for Adults with Asthma. Am J Prev Med. 2010;39:403-10.

[17] Osterholm MT, Kelley NS, Sommer A, Belongia EA. Efficacy and effectiveness of influenza vaccines: a systematic review and meta-analysis (vol 12, pg 36, 2012). Lancet Infect Dis. 2012;12:655-.

[18] Zaman K, Roy E, Arifeen SE, Rahman M, Raqib R, Wilson E, et al. Effectiveness of maternal influenza immunization in mothers and infants. The New England journal of medicine. 2008;359:1555-64. 
[19] Carman WF, Elder AG, Wallace LA, McAulay K, Walker A, Murray GD, et al. Effects of influenza vaccination of health-care workers on mortality of elderly people in long-term care: a randomised controlled trial. Lancet. 2000;355:93-7.

[20] Potter J, Stott DJ, Roberts MA, Elder AG, Odonnell B, Knight PV, et al. Influenza vaccination of health care workers in long-term-care hospitals reduces the mortality of elderly patients. Journal of Infectious Diseases. 1997;175:1-6.

[21] Beutels P, Edmunds WJ, Antonanzas F, De Wit GA, Evans D, Feilden R, et al. Economic evaluation of vaccination programmes: a consensus statement focusing on viral hepatitis. PharmacoEconomics. 2002;20:1-7.

[22] Cleemput I, Neyt M, Van De Sande S, Thiry N. Belgian guidelines for economic evaluations and budget impact analyses: second edition. Brussel: Federaal Kenniscentrum voor de Gezondheidszorg (KCE) . KCE Reports 183C. 2012.

[23] Skowronski DM, De Serres G. Is routine influenza immunization warranted in early pregnancy? Vaccine. 2009;27:4754-70.

[24] Briggs A, Sculpher M, Claxton K. Decision Modelling for Health Economic Evaluation. Oxford: Oxford University Press; 2006.

[25] World Health Organization (WHO). Threshold values for intervention cost-effectiveness by Region. http://www.who.int/choice/costs/CER levels/en/index.html2012.

[26] de Waure C, Veneziano MA, Cadeddu C, Capizzi S, Specchia ML, Capri S, et al. Economic value of influenza vaccination. Hum Vaccin Immunother. 2012;8:119-29.

[27] Jit M, Newall AT, Beutels P. Key issues for estimating the impact and cost-effectiveness of seasonal influenza vaccination strategies. Human vaccines \& immunotherapeutics. 2013;9:834-40.

[28] Burls A, Jordan R, Barton P, Olowokure B, Wake B, Albon E, et al. Vaccinating healthcare workers against influenza to protect the vulnerable - Is it a good use of healthcare resources? A systematic review of the evidence and an economic evaluation. Vaccine. 2006;24:4212-21.

[29] Treanor JJ, Talbot HK, Ohmit SE, Coleman LA, Thompson MG, Cheng PY, et al. Effectiveness of Seasonal Influenza Vaccines in the United States During a Season With Circulation of All Three Vaccine Strains. Clinical infectious diseases : an official publication of the Infectious Diseases Society of America. 2012.

[30] Skowronski DM, Tweed SA, De Serres G. Rapid decline of influenza vaccine-induced antibody in the elderly: is it real, or is it relevant? Journal of Infectious Diseases. 2008;197:490-502.

[31] Janjua NZ, Skowronski DM, De Serres G, Dickinson J, Crowcroft NS, Taylor M, et al. Estimates of influenza vaccine effectiveness for 2007-2008 from Canada's sentinel surveillance system: crossprotection against major and minor variants. Journal of Infectious Diseases. 2012;205:1858-68.

[32] Englund JA, Walter E, Black S, Blatter M, Nyberg J, Ruben FL, et al. Safety and immunogenicity of trivalent inactivated influenza vaccine in infants: a randomized double-blind placebo-controlled study. Pediatric Infectious Disease Journal. 2010;29:105-10.

[33] Belgisch Centrum voor Farmacotherapeutische Informatie. Gecommentarieerd Geneesmiddelenrepertorium. http://www.bcfi.be/ggr/index.cfm?ggrWelk=MAIN2012. [34] O'Brien BJ, Goeree R, Blackhouse G, Smieja M, Loeb M. Oseltamivir for treatment of influenza in healthy adults: pooled trial evidence and cost-effectiveness model for Canada. Value Health. 2003;6:11625. 